\title{
Determination of Novel Anti-Cancer Agents by Targeting OGG1 Enzyme Using Integrated Bioinformatics Methods
}

\author{
Ziyad Tariq Muhseen ${ }^{1,2}\left(\mathbb{D}\right.$, Mustafa Hussein Ali ${ }^{3}\left(\mathbb{D}\right.$, Nawar Rushdi Jaber ${ }^{4}$, Dheyaa Shakir Mashrea ${ }^{5}$, \\ Ali Mamoon Alfalki ${ }^{6}$ and Guanglin $\mathrm{Li}^{1,2, *(D)}$
}

1 School of Life Sciences, Shaanxi Normal University, Xi'an 710062, China; ziyad.tariq82@gmail.com

2 Key Laboratory of Ministry of Education for Medicinal Plant Resource and Natural Pharmaceutical Chemistry, Shaanxi Normal University, Xi'an 710062, China

3 School of Life Science and Technology, Huazhong University of Science and Technology, Wuhan 430074, China; m.bio24@yahoo.com

4 Department of Medical Laboratory Techniques, School of Life Sciences, Dijlah University College, Baghdad 00964, Iraq; Biomoon.n@gmail.com

5 Educational Directorate of Babylon Province, Ministry of Education, Babylon 51002, Iraq; dheyaashakir88@gmail.com

6 Department of Health Professional Graduate, University of New England, Biddeford, Portland, ME 04005, USA; aalfalki@une.edu

* Correspondence: glli@snnu.edu.cn; Tel.: +86-139-9285-6645

check for

updates

Citation: Muhseen, Z.T.; Ali, M.H.; Jaber, N.R.; Mashrea, D.S.; Alfalki, A.M.; Li, G. Determination of Novel Anti-Cancer Agents by Targeting OGG1 Enzyme Using Integrated Bioinformatics Methods. Int. J. Environ. Res. Public Health 2021, 18, 13290. https://doi.org/10.3390/ ijerph182413290

Academic Editor: Romina Combi

Received: 30 October 2021

Accepted: 13 December 2021

Published: 16 December 2021

Publisher's Note: MDPI stays neutral with regard to jurisdictional claims in published maps and institutional affiliations.

Copyright: (c) 2021 by the authors. Licensee MDPI, Basel, Switzerland. This article is an open access article distributed under the terms and conditions of the Creative Commons Attribution (CC BY) license (https:/ / creativecommons.org/licenses/by/ $4.0 /)$.
Abstract: The 8-oxoguanine DNA glycosylase (OGG1) enzyme is a key DNA glycosylase mediating the excision of 7,8-dihydro-8-oxoguanine (8-oxoG) from DNA molecule to the start base excision repair pathway. The OGG1 glycosylase function depletion has been seen to obstruct pathological conditions such as inflammation, A3 T-cell lymphoblastic acute leukemia growth, and neurodegenerative diseases, thus warranting OGG1 as an attractive anti-cancer enzyme. Herein, we employed several drug libraries intending to screen non-toxic inhibitory molecules against the active pocket of the enzyme that achieved stable binding mode in dynamics. Two anti-cancer compounds ([O] $\mathrm{C} 1=\mathrm{C}(\mathrm{CC} 2=\mathrm{CC}=\mathrm{CC}=\mathrm{C} 2) \mathrm{SC}(=[\mathrm{N}+] 1 \mathrm{CC}(=\mathrm{O}) \mathrm{NC} 3=\mathrm{NC}=\mathrm{C}(\mathrm{CC} 4=\mathrm{CC}=\mathrm{CC}=\mathrm{C} 4) \mathrm{S} 3) \mathrm{S}$ and $\mathrm{CCCN}(\mathrm{CCC})[\mathrm{S}]$ $(=\mathrm{O})(=\mathrm{O}) \mathrm{C} 1=\mathrm{CC}=\mathrm{C}(\mathrm{C}=\mathrm{C} 1) \mathrm{C}(=\mathrm{O}) \mathrm{NNC} 2=\mathrm{NC} 3=\mathrm{CC}=\mathrm{C}(\mathrm{Br}) \mathrm{C}=\mathrm{C} 3 \mathrm{C}(=\mathrm{N} 2) \mathrm{C} 4=\mathrm{CC}=\mathrm{CC}=\mathrm{C} 4)$ from Selleckchem.com were identified to occupy the active pocket of OGG1 and bind with greater affinity than Control TH5487. The binding affinity of Top-1 is $-11.6 \mathrm{kcal} / \mathrm{mol}$ while that of Top-2 is $-10.7 \mathrm{kcal} / \mathrm{mol}$ in contrast to TH5487 Control $(-9 \mathrm{kcal} / \mathrm{mol})$. During molecular dynamic simulations versus time, the said compounds are tightly held by the enzyme with no minor structural deviations reported except flexible loops in particular those present at the $\mathrm{N}$ and C-terminal. Both the compounds produced extensive hydrophobic interactions with the enzyme along with stable hydrogen bonding. The docking and molecular dynamics simulations predictions were further validated by molecular mechanics with generalized Born and surface area solvation (MM/GBSA) and Poisson Boltzmann surface area (MM/PBSA), and WaterSwap binding energies that validated strong binding of the compounds to the enzyme. The MM/GBSA binding free energy for Top-1 complex is $-28.10 \mathrm{kcal} / \mathrm{mol}$, Top-2 complex is $-50.14 \mathrm{kcal} / \mathrm{mol}$ ) and Control is $-46.91 \mathrm{kcal} / \mathrm{mol}$ while MM/PBSA value for Top-1, Top-2 and Control is $-23.38 \mathrm{kcal} / \mathrm{mol},-35.29 \mathrm{kcal} / \mathrm{mol}$ and $-38.20 \mathrm{kcal} / \mathrm{mol}$, respectively. Computational pharmacokinetics support good druglike candidacy of the compounds with acceptable profile of pharmacokinetics and very little toxicity. All these findings support the notion that the compounds can be used in experiments to test their anti-cancer activities.

Keywords: base excision repair; binding free energies; glycosylase inhibitor; MD simulations; molecular docking; TH5487

\section{Introduction}

Reactive oxygen species (ROS) are the product of exogenous and endogenous sources, the latter ROS are generated as a by-product of oxygen metabolism in the endoplasmic 
reticulum, mitochondria, and peroxisomes [1]. It has been well established that many pathological diseases such as aging, cardiovascular diseases, cancer, neurodegenerative diseases, inflammatory diseases, and ischemia-reperfusion injury result in loss of balanced redox homeostasis [2,3]. ROS in appropriate concentrations function in immune responses and signaling pathways; however, when ROS concentration reaches a higher level, they overwhelm the antioxidant potential of the cells, which in turn results in oxidative stress leading to oxidative damage to the DNA, protein, and lipids $[3,4]$.

Under low redox conditions, guanine is sensitive to oxidation, transforming it to 7,8-dihydro-8-oxoguanine (8-oxoG) thus causing a genetic mutation [5]. In such a situation, 8-oxoguanine DNA glycosylase (OGG1) enzyme performed excision of 8-oxoG and along with PARP1 initiated base excision repair (BER) pathway, which has been involved in repairing the majority of DNA lesions [6]. Previous data revealed that availability of four approved PARP inhibitors to treat homologous recombination defective cancers [7]. These inhibitors interfere with alternative end-joining pathways [8] and replication forks [9]. The OGG1 enzyme of the BER pathway is less explored as an anti-cancer target. Recent studies indicated that inhibiting OGG1 by a potent small molecule, TH5487, SU0268 (https: //www.medchemexpress.com/su0268.html (accessed on 8 December 2021)) and O8 (https: //www.tocris.com/products/o8-ogg1-inhibitor_6236 (accessed on 8 December 2021)), effectively targets OGG1 enzyme and thus can serve beneficial approach for targeting oxidative DNA repair and alleviating cancer pathologies [10,11].

In the current study, considering the high potential of OGG1 as a druggable enzyme prompts us to devise a computational study to perform structure-based virtual screening of different natural and synthetic drug libraries with the ultimate aim to identify potent OGG1 inhibitors. OGG1 is a druggable enzyme as it can be targeted by drugs that can modulate its function. Computational tools in modern drug discovery play a major role in the development of therapeutically important drugs [12,13]. The in silico tools aid in the rational design of safe and new drugs and limit the use of animal models $[14,15]$. The study objectives include filtering several drug libraries including anti-cancer compounds (Selleckchem anti-cancer compound library I and II), plus libraries of natural compounds including medicinal plant database (MDP3) [16], Asinex targeted oncology database, and comprehensive marine natural products database (CMNPD), first on toxicity where toxic molecules were discarded. Toxic compounds offer failure at several stages of the drug discovery process and waste the invested costs, time, and human efforts [17-19]. Secondly, molecular docking was applied to virtual screen the mentioned non-toxic drug molecules against the OGG1 active pocket [20,21]. Further, the shortlisted best inhibitors were complexed with the enzyme and tested in dynamics conditions to evaluate binding conformation and binding interactions stability as a function of time. Extensive, all-atoms molecular dynamics simulation studies were performed for selected complexes [22,23] and intermolecular interactions energies were estimated by molecular mechanics with generalized Born and surface area solvation (MM/GBSA) and Poisson-Boltzmann surface area (MM/GBSA) methods [24,25], which were cross-validated by a further improved WaterSwap free energy method [26,27]. Overall, the study identified two novel drug molecules with good binding potential against OGG1 and therefore needs to be subjected to experimental studies.

\section{Results}

To evaluate the binding affinity of the filtered libraries' compounds for the OGG1 enzyme, structure-based virtual screening was conducted. The active site information was retrieved from crystal structure of the enzyme reported with TH5487 inhibitor [10]. Performing virtual screening of the libraries containing approximately 46,283 molecules took about 1 month. The compound binding potential to the enzyme was measured first in terms of the GOLD fitness score that takes into account chemical forces build as a result docked conformation between the compound and the enzyme. A high GOLD fitness score determines better binding affinity of the compounds and vice versa. Top-ranked 10 molecules 
were redocked to the enzyme three times and each time the scoring function was changed to ASP (the Astex Statistical Potential), CHEMPLP, and ChemScore. Details about these scoring functions can be found on the GOLD docking software official page (https: / www. ch.cam.ac.uk/computing/software/gold-suite(assessed on 8 December 2021). Top-10 docked inhibitors at the active pocket of the receptor enzyme predicted by GOLD docking software are shown in Figure S1. It can be easily observed that these virtually screened compounds are docked well inside at the active pocket of the enzyme. In parallel, Top-10 compounds binding energy was determined using AutoDock Vina to strengthen our docking predictions. Two compounds $([\mathrm{O}-] \mathrm{C} 1=\mathrm{C}(\mathrm{CC} 2=\mathrm{CC}=\mathrm{CC}=\mathrm{C} 2) \mathrm{SC}(=[\mathrm{N}+] 1 \mathrm{CC}(=\mathrm{O}) \mathrm{NC} 3=\mathrm{NC}=\mathrm{C}-$ $(\mathrm{CC} 4=\mathrm{CC}=\mathrm{CC}=\mathrm{C} 4) \mathrm{S} 3) \mathrm{S}$ and $\mathrm{CCCN}(\mathrm{CCC})[\mathrm{S}](=\mathrm{O})(=\mathrm{O}) \mathrm{C} 1=\mathrm{CC}=\mathrm{C}(\mathrm{C}=\mathrm{C} 1) \mathrm{C}(=\mathrm{O}) \mathrm{NNC} 2=\mathrm{NC} 3-$ $=\mathrm{CC}=\mathrm{C}(\mathrm{Br}) \mathrm{C}=\mathrm{C} 3 \mathrm{C}(=\mathrm{N} 2) \mathrm{C} 4=\mathrm{CC}=\mathrm{CC}=\mathrm{C} 4)$ were selected as the best inhibitors of the enzyme compared to the Control TH5487, SU0268, and O8. The GOLD fitness scores of Top1 and Top-2 are 79 and 76, respectively, while their AutoDock Vina binding energy is $-11.6 \mathrm{kcal} / \mathrm{mol}$ and $-10.7 \mathrm{kcal} / \mathrm{mol}$, respectively. In case of negative Controls, the binding affinity of TH2840 or TH5411 was $-8.61 \mathrm{kcal} / \mathrm{mol}$ and $-8.01 \mathrm{kcal} / \mathrm{mol}$, respectively. The different docking scores of the Control and compounds are tabulated in Table 1.

Table 1. Virtually screened compounds and their docking scores.

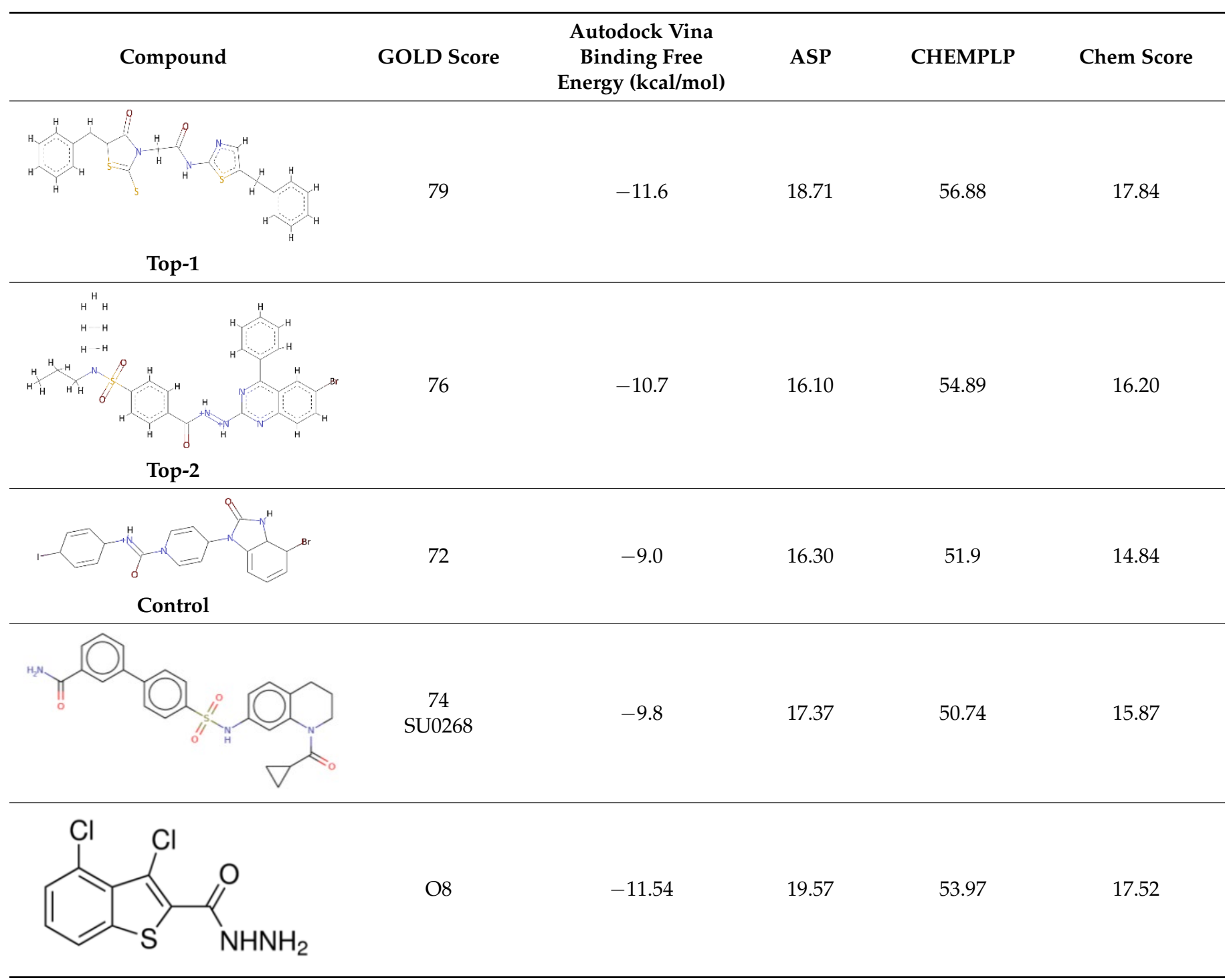

The Control TH5487 molecule's GOLD fitness score is 72 and its binding energy value is $-9.0 \mathrm{kcal} / \mathrm{mol}$. Both hydrogen bonding and van der Waals interactions are reported 
at the active pocket by the Control. Cys243, Val259, and Hie260 are hydrogen bonding residues with distance lengths of $4.02 \AA, 3.8 \AA$, and $4.54 \AA$, respectively. While Gly 32 , Gln33, Lys239, Val257, Asp309, Hie263, and Gly32 formed van der Waals interactions with the compound. Besides these, Phe134, Leu246, Pro256, Phe306, and Leu310 were noticed in different alkyl interactions. Interestingly, the docked site of the compounds and the Control remain the same and interact with an almost similar set of active pocket residues. The binding mode of Control and its interactions with the active site residues are shown in Figure $1 \mathrm{~A}$.

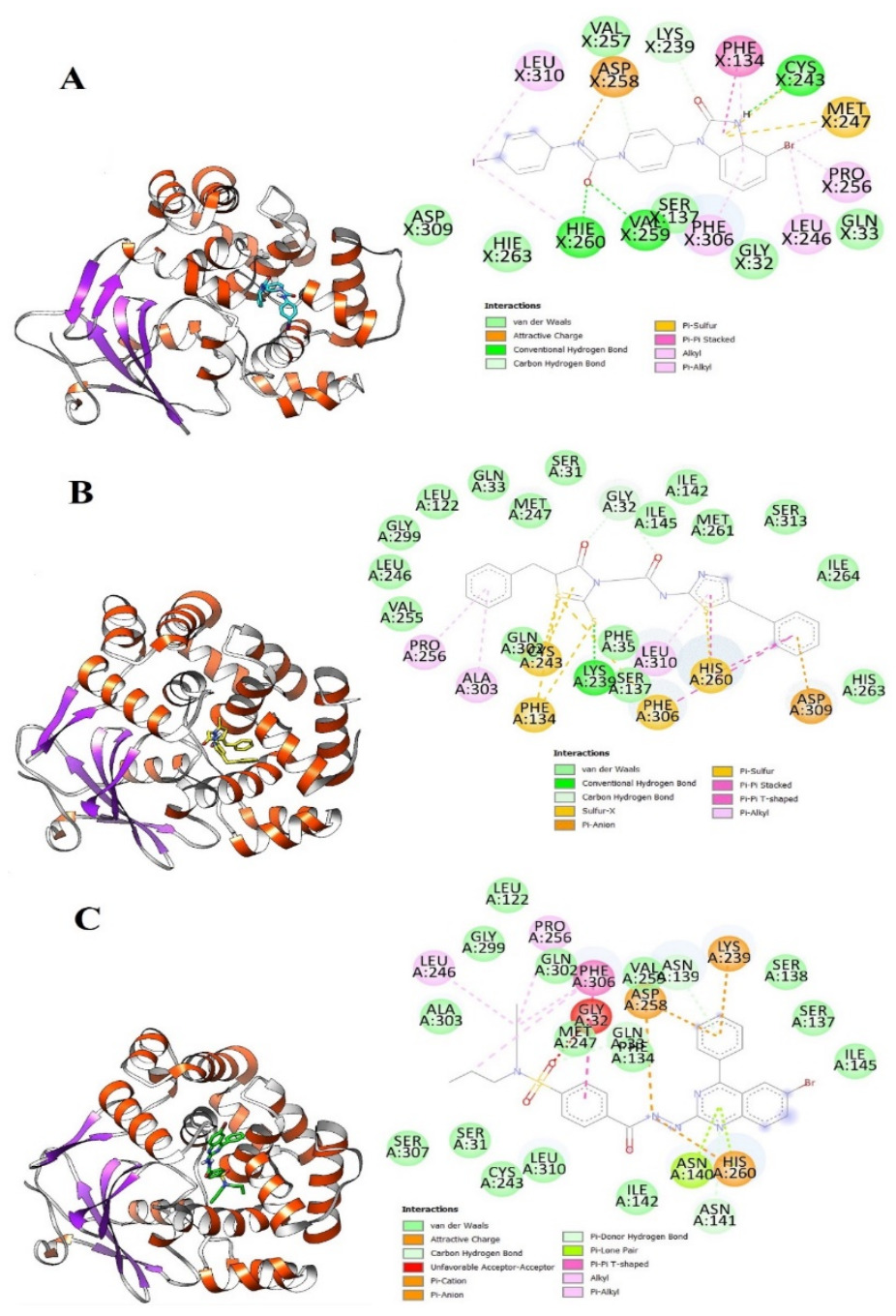

Figure 1. Molecular docking analysis of Control and shortlisted best binders. Both intermolecular docking conformation and interactions are provided. (A) 3D conformation of Control (shown in cyan stick), (B) Top-1 (shown in yellow stick), and (C) Top-2 (shown in green stick) at the active pocket of OGG1 enzyme (shown in secondary structure ribbon), and 2D presentation of enzyme residues interaction with the compounds.

Top-1 interactions at the docked active cavity are dominated by van der Waals. These interactions are formed along the length of the compound where the central oxygen and nitrogen atoms are engaged by hydrogen bonding in particular with Lys239 (distance length is $2.3 \AA$ ). The end benzene on one side produced interactions of van der Waals and pi-anion while the on the other side make pi-alkyl and van der Waals. The central sulfur atoms of the compounds interact with Cys243, and Phe134 through sulfur bonding. From all around, the compound is strongly held at the active pocket and favors interactions with 
majority of the active pocket residues (Figure 1B). A rich cluster of chemical interactions is also noticed between Top-2 compound and the receptor enzyme (Figure 1C).

\subsection{Molecular Dynamics Simulations}

Molecular dynamic simulation studies determine the dynamic behavior of atoms or macromolecules in a specific time and special environment. Both selected complexes (GOLD docked pose) and Control were performed to validate structural stability of the enzyme in the presence of compounds. This was also essential to look for stable binding of the compounds at the docked site throughout the length of simulation time, which is key for altering the biological function of the enzyme and to get desired results [22]. The simulation trajectories were evaluated through several statistical parameters (Figure 2). First, root mean square deviation (RMSD) $[28,29]$ was performed that examined all carbon alpha deviation versus time scale considering the initial input intermolecular conformation as reference (Figure 2A). Lower RMSD implies fewer deviations in the system, whereas higher RMSD corresponds to more structural fluctuations. Larger biological systems usually follow higher RMSD, but a constant trend indicates their stable nature.

A

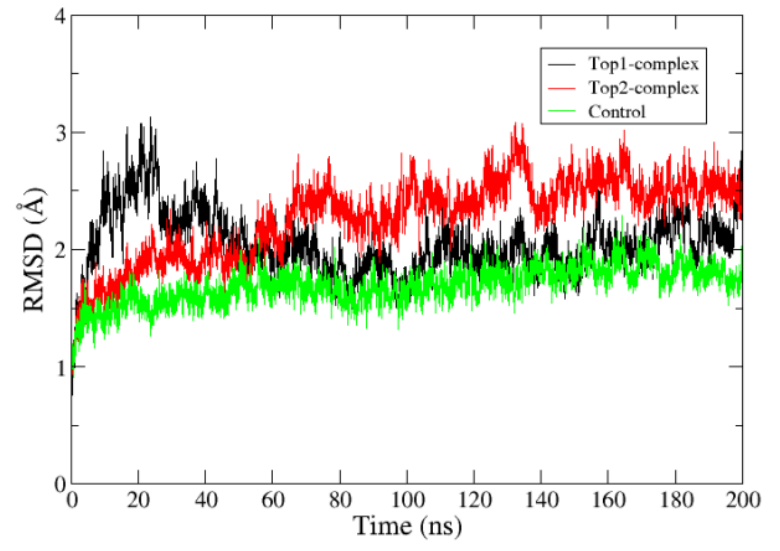

C

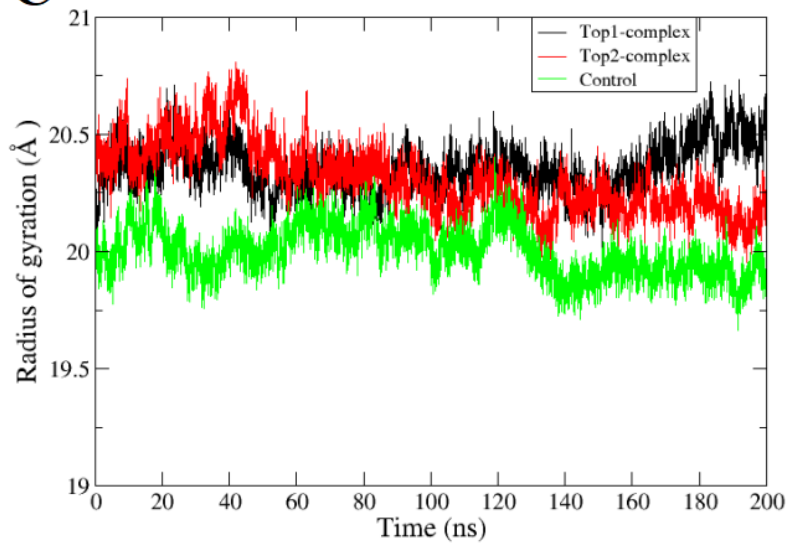

B

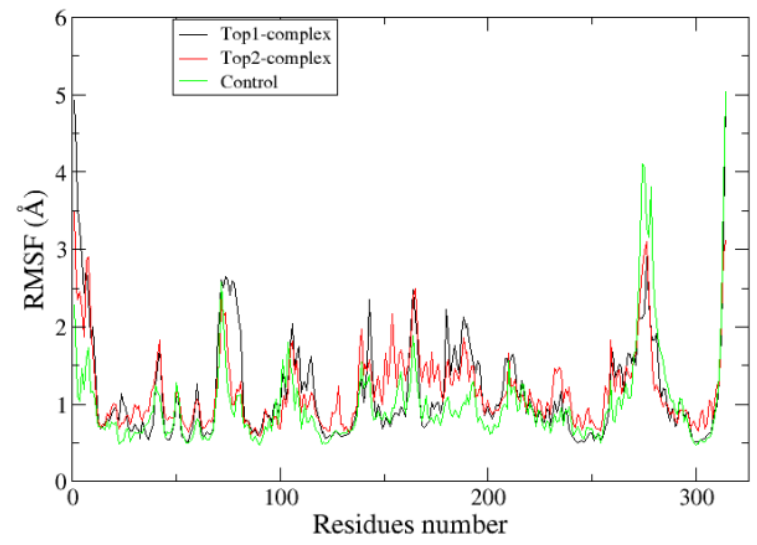

D

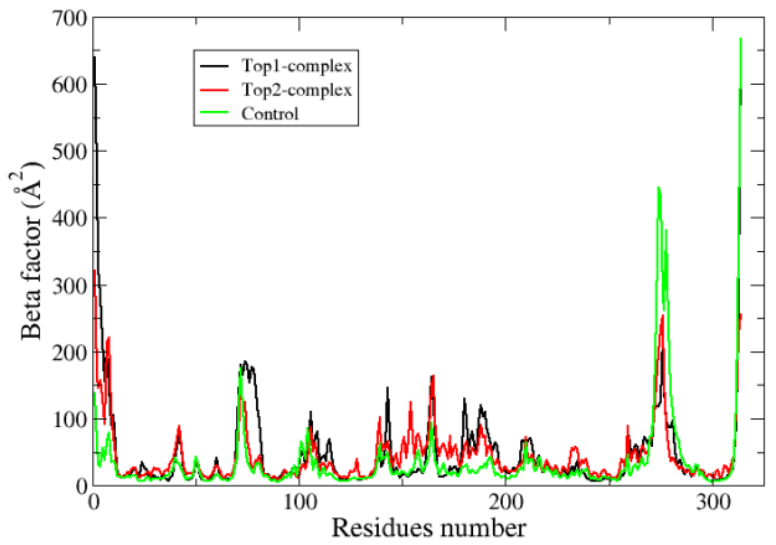

Figure 2. Molecular dynamic simulation analysis. All provided analysis are done based on carbon alpha atoms. The structural dynamics of complexes are given as a function of time. (A) RMSD, (B) RMSF, (C) Rg, and (D) B-factor.

The Figure 2A shows that compounds are in good equilibration and the stability is more strongly towards the end of simulation time. The Control was reported with an excellent RMSD plot and is a demonstration of greater intermolecular strength. The mean RMSD of Top-1, Top-2, and Control complexes is $1.68 \AA$, $2.04 \AA$, and $2.27 \AA$, respectively. The Top-1 compound enzyme is seen as not stable until 52 ns, as it experienced deviations touch 3.1 A. Following this, the system remained in stable RMSD until the end of simulation 
time. Top-2 compound had a lower RMSD until 60 ns and then behaved inconsistently with maximum RMSD of $3 \AA$, and after 140 ns the system became stable. These acceptable RMSD variations upon snapshots visualization identified that compounds are trying to stabilize their binding conformation at the active pocket by giving flexibility to some of its chemical moieties, which forces the enzyme flexible loops to lose their original XYZ coordinates $[30,31]$. To validate the stability of the systems, the simulation was run in duplicate with a different initial velocity. A very similar trend was noticed except for few up and down trends (Figure S2). To infer time dependent enzyme residue fluctuations in the presence of inhibitors, root mean square fluctuation (RMSF) was calculated (Figure 2B). The mean RMSF of the systems is as Top-1 complex (1.16 $⿱$ )), Top-2 complex (1.15 $)$ ), and Control $(0.99 \AA)$. These RMSF values agree on high stable nature of the complexes, in particular the Control. Higher RMSF values were recorded for the $\mathrm{N}$-terminal and C-terminal residues covering large loops; they are more flexible than the rest of the enzyme regions. The active pocket residue remained highly stable in the presence of the compounds. The radius of gyration $(\mathrm{Rg})$ [32] was also taken into consideration as given in Figure 2C. $\mathrm{Rg}$ is a statistical value describing the strength of atoms packing in a protein. The lower value and the decline in the $\mathrm{Rg}$ value for all complexes is suggestive of stabilization and compactness aided by the binding of ligands to the target protein. The mean $\mathrm{Rg}$ of systems is $\sim 20 \AA$ and follows the same trend as noticed in RMSD. Beta factor (B-factor) analysis [33] was done to investigate thermal stability of the enzyme residues (Figure 2D). This analysis replicates the RMSF findings and confirmed the $\mathrm{C}$ and $\mathrm{N}$-terminal have more flexibility than the rest of the enzyme structure. To validate the binding site stability of the compounds, a superimposition of last frame of molecular dynamics simulation over docked enzyme-compound structure was performed as can be seen in Figures S3 and S4. In both cases, it was noticed that the compounds occupied the binding pocket until the end of simulation time and remained in contact with the enzyme active site residues.

\subsection{Hydrogen Bonds Analysis}

In drug designing against any particular biological macromolecule, hydrogen bonding plays a significant role in three ways [34]. First, it stabilizes the binding of a compound to the binding receptor partner. Second, it aids in chemical recognition of the compounds, and third, it determines compound binding affinity, which is key to success in drug development. Throughout the the simulation, the number of hydrogen bonds formed by both compounds as well Control is presented in Figure 3. As can be seen, the compounds and Control are strongly engaged by at least one hydrogen bond in each frame of simulation trajectories. This signifies the high intermolecular affinity of the docked compounds and OGG1 enzyme. These hydrogen bondings were seen between highly electronegative atoms of the compounds/Control and close distance active site residues presented in RDF analysis. 


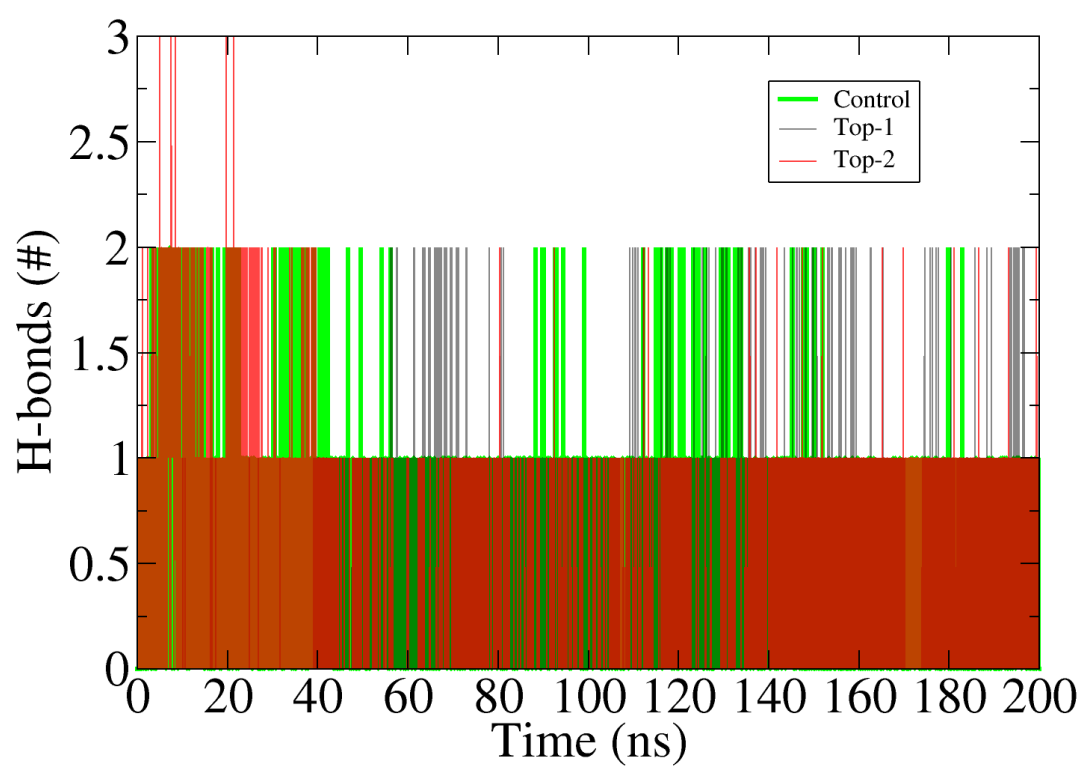

Figure 3. Hydrogen bonds analysis in each frame of simulation time. The bar figure provides number of hydrogen bonds established between the compounds and enzyme during simulation time.

\subsection{Radial Distribution Function-g(r)}

Determining interatomic interaction density during simulation time is important in several ways for stable interactions of the compounds with the enzyme [35]. It helps in highlighting constant interactions vital for holding compounds at the enzyme docked site and shedding light on the distance at which maximum interactions density is produced [36]. Before running g(r) analysis, an in-house Perl written script was used in visual molecular dynamics (VMD) [37], which was run on all simulation trajectories loaded on systems prmtop. The close distance hydrogen bonds and van der Waals bonds between the compounds and the OGG1 enzyme were filtered and subjected Assisted Model Building with Energy Refinement (AMBER) CPPTRAJ to generate g(r) plots. Only interactions that are important in ligand binding to the enzyme active pocket and regularly seen during simulation frames were selected for RDF analysis. For Control, residues like Ser31, Phe134, Ser137, Lys239, Cys243, Met247, Val250, Asp258, Val257, and Hie260 were seen in regular contacts with the Control O2, and $\mathrm{H} 7$ atoms throughout simulation time. At different time points, the $\mathrm{g}(\mathrm{r})$ plots describing the mentioned residues interactions with the Control atoms are presented in Figure 4A. The maximum $\mathrm{g}(\mathrm{r})$ reported for Ser137 oxygen atom to Control $\mathrm{H} 7$ and Hie 260 and Control $\mathrm{O} 2$ atom towards the end of simulation. This means that at the end of simulation time, these two interactions are key stable binding of the Control and play a critical contribution in the initial times. For Top-1, Ser31, Gly32, Lys239, and Met261 are vital in interactions with the compound's highly electronegative atoms in particular oxygen and nitrogen (Figure 4B). The Ser31, Gly32, and Lys239 interaction density with Top-1 atoms were reported maximum at distance $\sim 4 \AA$. In case of Top-2, enzyme active pocket residues like Ser137, Asp258, Lys239, His260, Asn140, and Ile142 are among the notable residues engaging the compound (Figure 4C). Ser137, Asn140, Asp258, and Hie260 were found to have highest interatomic interaction density distribution at $\sim 1.8-1.9 \AA$. 
A

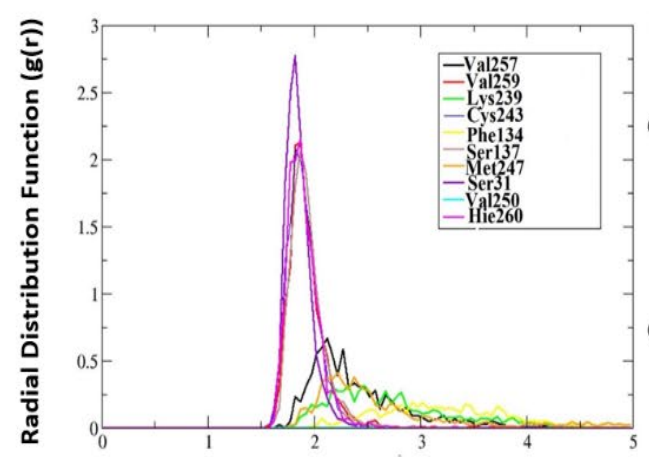

$\propto$

\section{B}

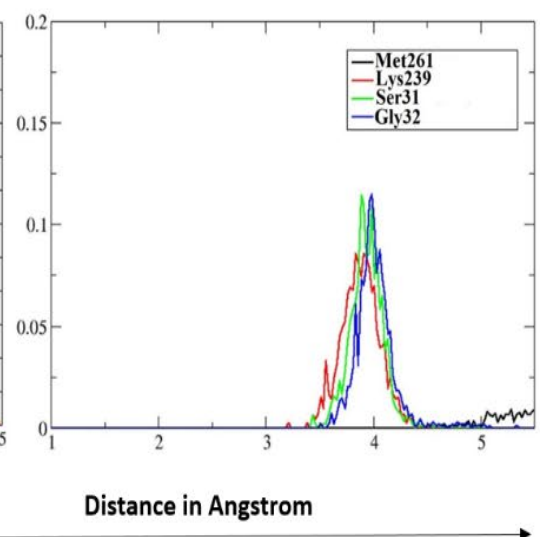

C

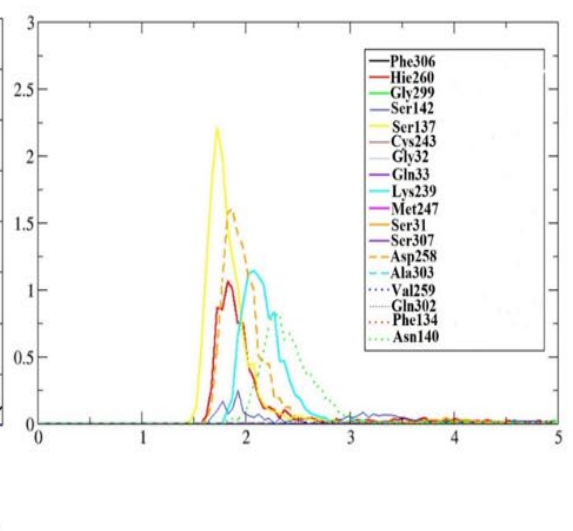

Figure 4. Radial distribution analysis of hydrogen bonds/van der Waals formed between the compounds and enzyme active site residues. (A) Control, (B) Top-1, and (C) Top-2. Only key interactions are plotted in radial distribution analysis.

\section{4. $M M / G B S A$ and MM/PBSA Binding Free Energies}

Next, binding free energies of the complexes were estimated using two popular approaches: MM/GBSA and MM/PBSA. Both approaches are now routinely applied in many drug designing works to decipher compounds real binding potential. The advantage of these end point techniques is their low computational power need and their potential to generate reproducible results comparable to experimental findings [38,39]. In the MM/GBSA method, the total binding energy of the complexes is the same as Top-1 complex $(-28.10 \mathrm{kcal} / \mathrm{mol})$, Top-2 complex $(-50.14 \mathrm{kcal} / \mathrm{mol})$ and Control $(-46.91 \mathrm{kcal} / \mathrm{mol})$. The MM/GBSA has ranked compound 2 as the most effective binder of OGG1 enzyme, followed by Control and Top-1. For all three complexes, van der Waals energy was seen dominant while electrostatic energy favors the binding. As a result of significant contribution from both van der Waals and electrostatic energy, the net gas phase of the systems is quite promising and denotes the systems overall equilibrium nature. On the other hand, net solvation energy is non-favorable mainly due to polar solvation energy. The non-polar energy seems to contribute to systems stability. In MM/PBSA, the Control complex is a bit more stable than compound 2 and compound 1. Similarly, MM/GBSA, MM/PBSA also interpreted the domination of van der Waals and electrostatic energies while highly non-favorable contributions were derived from polar solvation energy. The total MM/PBSA energy of Top-1, Top-2 and Control is $-23.38 \mathrm{kcal} / \mathrm{mol},-35.29 \mathrm{kcal} / \mathrm{mol}$ and $-38.20 \mathrm{kcal} / \mathrm{mol}$, respectively. The different binding free energies of the complexes are tabulated in Table 2 . The entropy energy for systems is Control $(10 \mathrm{kcal} / \mathrm{mol})$, Top-1 $(11 \mathrm{kcal} / \mathrm{mol})$ and Top-2 $(8 \mathrm{kcal} / \mathrm{mol})$. These findings complement the aforementioned analysis well in demonstrating the good binding capacity of the compounds for the OGG1 enzyme, and are likely to compete with natural ligands to block the enzyme activity and prevent cancers. 
Table 2. MM/GBSA and MM/PBSA binding free energy estimated from 500 frames of molecular dynamics simulation. The net binding free energy value is decomposed further into respective electrostatic, van der Waals, polar, and non-polar solvation energies.

\begin{tabular}{|c|c|c|c|c|c|c|c|}
\hline \multicolumn{8}{|c|}{ MM/GBSA } \\
\hline Compound & $\begin{array}{l}\Delta \text { G Binding } \\
\text { (kcal/mol) }\end{array}$ & $\begin{array}{c}\Delta \mathrm{G} \\
\text { Electrostatic } \\
(\mathbf{k c a l} / \mathrm{mol})\end{array}$ & $\begin{array}{c}\Delta \text { G Bind van } \\
\text { der Waals } \\
\text { (kcal/mol) }\end{array}$ & $\begin{array}{c}\Delta \text { G Gas Phase } \\
\text { (kcal/mol) }\end{array}$ & $\begin{array}{l}\Delta \text { G Polar } \\
\text { Solvation } \\
\text { (kcal/mol) }\end{array}$ & $\begin{array}{c}\Delta \text { G Non-Polar } \\
\text { Solvation } \\
\text { (kcal/mol) }\end{array}$ & $\begin{array}{c}\Delta \text { G Solvation } \\
\text { (kcal/mol) }\end{array}$ \\
\hline Top-1 & -28.10 & -25.26 & -41.42 & -66.69 & 44.40 & -5.80 & 38.59 \\
\hline Top-2 & -50.14 & -17.00 & -60.47 & -77.47 & 34.54 & -7.21 & 27.32 \\
\hline Control & -46.91 & -23.10 & -56.70 & -79.81 & 38.54 & -5.64 & 32.90 \\
\hline \multicolumn{8}{|c|}{ MM/PBSA } \\
\hline Top-1 & -23.38 & -25.26 & -41.42 & -66.69 & 47.85 & -4.54 & 43.30 \\
\hline Top-2 & -35.29 & -17.00 & -60.47 & -77.47 & 47.50 & -5.32 & 42.17 \\
\hline Control & -38.20 & -23.10 & -56.70 & -79.81 & 45.55 & -3.94 & 41.60 \\
\hline
\end{tabular}

\subsection{Decomposition of MM/GBSA Binding Energy}

The net MM/GBSA binding free energy was decomposed into the enzyme residues to shed light on the hotspot residue contributing majorly to binding with the compounds during simulation time $[26,40]$. The different residues that are involved in regular binding with the compounds and highly stable in complex formation are tabulated in Table 3. In both complex, the binding energy of ligand molecules is much lower than predicted by the AutoDock Vina and are therefore achieving greater stability when binding to the receptor enzyme. Majority of the hotspot residues in both complexes are part of the OGG1 enzyme active pocket. The residues interact hydrophobically and hydrophilically with the compounds.

Table 3. Net binding energy value of compounds and their interacting residues that are highly stable in complex formation in simulation time. The energy values are given in $\mathrm{kcal} / \mathrm{mol}$. Moreover, alanine scanning results when key compounds interacting residues are mutated to alanine. NA (not applicable).

\begin{tabular}{ccccc}
\hline Ligand/Residue & Top-1 & Alanine Scanning Results & Top-2 & Alanine Scanning Results \\
\hline Ligand & -15.06 & NA & -24.28 & NA \\
Ile142 & -3.209 & -2.14 & -4.38 & -2.80 \\
Phe134 & -1.90 & -1.20 & -2.74 & -1.11 \\
Phe306 & -1.77 & -0.98 & -2.84 & -1.44 \\
Ala143 & -1.19 & -1.0 & -1.75 & -1.12 \\
Cys243 & -0.97 & NA & -1.55 & NA \\
Gln33 & -0.82 & NA & -1.50 & NA \\
Ile145 & -0.80 & NA & -1.35 & NA \\
Met247 & -0.71 & NA & -1.28 & NA \\
His260 & -0.47 & 1.0 & -1.10 & -1.00 \\
Leu122 & -0.45 & NA & -0.87 & NA \\
Ala303 & -0.41 & NA & -0.80 & NA \\
Leu246 & -0.39 & NA & -0.73 & NA \\
Gly32 & -0.35 & -1.04 & -0.70 & -1.10 \\
Pro256 & -0.33 & -1.0 & -0.61 & -1.01 \\
Leu310 & -0.25 & NA & -0.55 & NA \\
Phe35 & -0.22 & 0.12 & -0.54 & -0.41 \\
Val240 & -0.21 & NA & -0.50 & NA \\
Ser31 & -0.21 & 0.11 & -0.48 & 1.18 \\
\hline
\end{tabular}

\subsection{WaterSwap Binding Energies}

Though there are several advantages of using MM-GBSA and MM-PBSA binding energy methods in drug designing process, yet they suffer from a few limitations that are critical to be considered. Among the most important is skipping the role of water molecules present in the enzyme active pocket especially in cases when the water molecules bridge 
the interactions between receptor and ligand [26]. To overcome this, we employed another popular binding free energy method in the work to get more confidence in our results. WaterSwap allows swapping of a ligand with an equal volume of water and thus is more sophisticated in terms of considering water molecules contribution in ligand binding. WaterSwap uses three algorithms namely, thermodynamics integration (TI), free energy perturbation (FEP), and BENNETTS to calculate binding free energy of a given complex. As can be noticed in Figure 5 the total binding energy value by each WaterSwap method is very converged with respect to each other and the values are quite low demonstrating highly stable binding of the compounds to the enzyme.

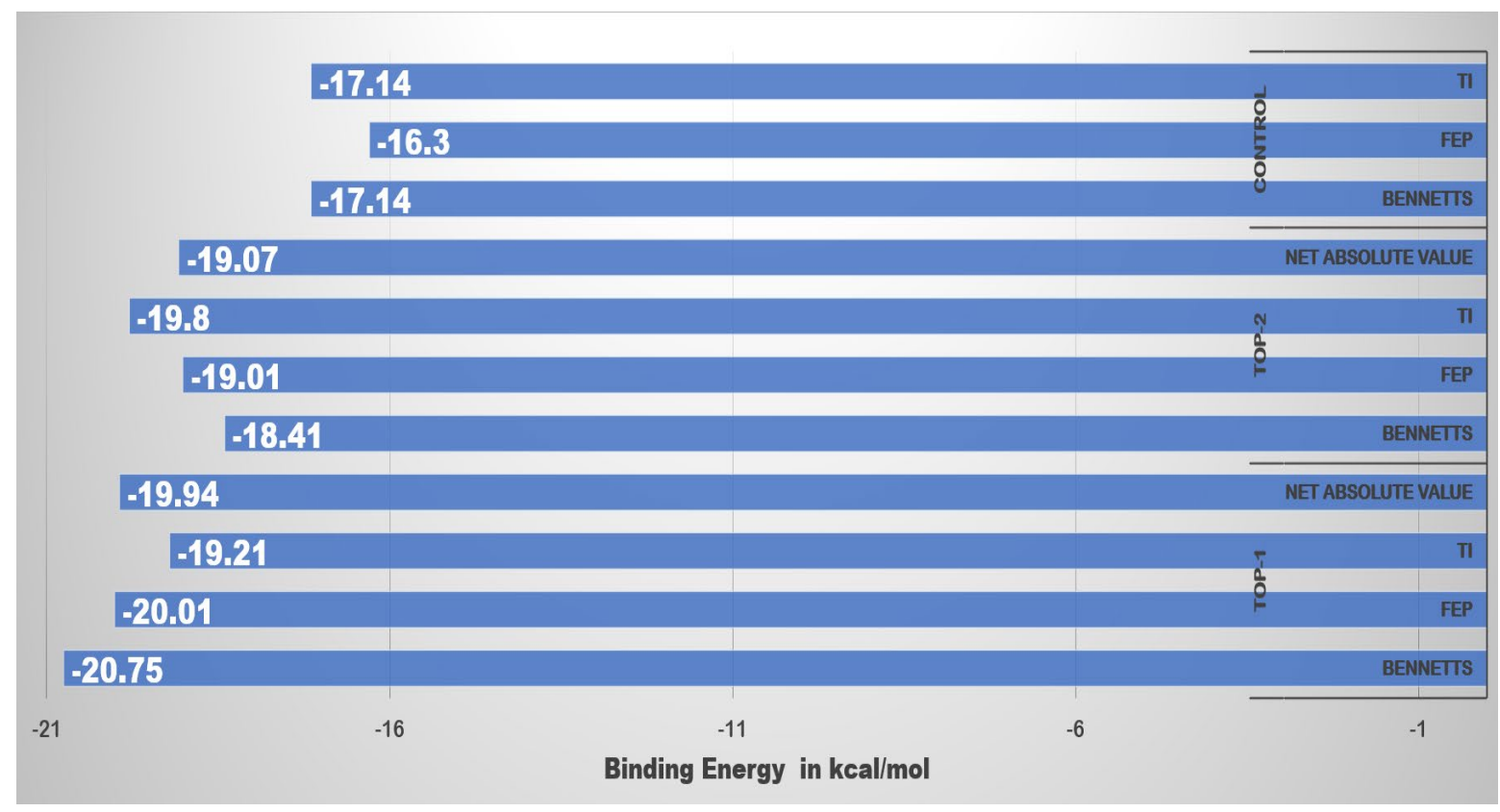

Figure 5. WaterSwap binding free energies are estimated by different methods such TI, FEP, and BENNETTS. The energy values are given in $\mathrm{kcal} / \mathrm{mol}$.

\subsection{In Silico Site Directed Mutagenesis}

In order to access the impact of mutations on the active pocket to bind compounds, site directed mutagenesis analysis was performed. It has been revealed that several residues are affecting stable binding conformation of the compounds upon mutation. The binding free energy of residues which is decreased after mutation is presented in Table 3. It is also noted that the binding proximity and conformation of the compounds remain the same; however, the binding strength is reduced due to absent of active residues chemical moieties which were present in the unmutated enzyme. These results supported the fact that enlisted residues are vital in compound binding, interactions, and overall conformation stability at the enzyme active pocket.

\subsection{Computational Pharmacokinetics Studies}

Computational predictions of the inhibitors' pharmacokinetics were carried out to guide structural optimization of the compounds to avoid their failure in clinical studies [41-43]. The results of this analysis are given in Table 4 . Both compounds are moderately soluble thus have good chances to be easily administered orally. The physicochemical properties of the compounds are favorable and thus can be good drug candidates. The topological polar surface area (TPSA) [44] of the compounds is within acceptable range, which can be improved further, in particular Top-1, to enhance their cell permeability potential and reach the target site for performing desired biological mechanisms. Fortunately, both compounds are much less toxic as per predictions, which makes them suitable against 
the targeted OGG1 enzyme. The compounds are predicted to show no hepatotoxicity, no Ames toxicity, and no skin sensitization, all in favor of the compounds to be utilized in further experimental testing against OGG1. Additionally, due to the simple structure of the compounds, they can be easily synthesized in bulk quantities and have no Pan-assay interference compounds (PAINS) alerts [45]. Because of good pharmacokinetic profiles of the compounds, they might serve as attractive drug molecules for blocking cancer cell proliferation. The compounds are also predicted to be non-toxic.

Table 4. Computational pharmacokinetics along with several pharmaceutically important parameters of the compounds.

\begin{tabular}{|c|c|c|c|}
\hline \multirow{2}{*}{$\begin{array}{c}\text { Property } \\
\text { Physicochemical Properties }\end{array}$} & \multicolumn{3}{|c|}{ Compounds } \\
\hline & Top-1 & Top-2 & Control \\
\hline Formula & C22H19N3O2S3 & C27H28BrN5O3S & C19H19BrIN4O2 \\
\hline Molecular weight & $453.60 \mathrm{~g} / \mathrm{mol}$ & $582.51 \mathrm{~g} / \mathrm{mol}$ & $542.19 \mathrm{~g} / \mathrm{mol}$ \\
\hline Num. heavy atoms & 30 & 37 & 27 \\
\hline Num. arom. heavy atoms & 22 & 22 & 11 \\
\hline Fraction Csp3 & 0.14 & 0.22 & 0.32 \\
\hline Num. rotatable bonds & 8 & 11 & 4 \\
\hline Num. H-bond acceptors & 3 & 6 & 2 \\
\hline Num. H-bond donors & 1 & 2 & 2 \\
\hline Molar Refractivity & 123.71 & 149.71 & 118.21 \\
\hline TPSA & $164.21 \AA^{2}$ & $112.67 \AA^{2}$ & $70.77 \AA^{2}$ \\
\hline \multicolumn{4}{|l|}{ Lipophilicity } \\
\hline Consensus Log Po/w & 4.22 & 5.00 & 2.38 \\
\hline Water Solubility & Moderately soluble & Moderately soluble & Moderately soluble \\
\hline \multicolumn{4}{|l|}{ Pharmacokinetics } \\
\hline GI absorption & High & High & High \\
\hline BBB permeant & No & No & Yes \\
\hline P-gp substrate & No & No & Yes \\
\hline CYP1A2 inhibitor & No & No & No \\
\hline CYP2C19 inhibitor & Yes & Yes & No \\
\hline CYP2C9 inhibitor & Yes & Yes & No \\
\hline CYP2D6 inhibitor & No & No & No \\
\hline CYP3A4 inhibitor & No & No & No \\
\hline Log Kp (skin permeation) & $-4.93 \mathrm{~cm} / \mathrm{s}$ & $-4.80 \mathrm{~cm} / \mathrm{s}$ & $-7.34 \mathrm{~cm} / \mathrm{s}$ \\
\hline \multicolumn{4}{|l|}{ Druglikensess } \\
\hline Lipinski & Yes; 0 violation & Yes; 1 violation: $\mathrm{MW}>500$ & Yes; 1 violation: $\mathrm{MW}>500$ \\
\hline \multicolumn{4}{|l|}{ Medicinal Chemistry } \\
\hline PAINS & 0 alert & 0 alert & 1 alert acyl_het_A \\
\hline Synthetic accessibility & 3.86 & 3.72 & 4.76 \\
\hline \multicolumn{4}{|l|}{ Toxicity } \\
\hline Hepatotoxicity & No & Yes & Yes \\
\hline Skin sensitisation & No & No & No \\
\hline T. pyriformis toxicity & $0.292 \log u g / L$ & $0.285 \log u g / L$ & $0.315 \log u g / L$ \\
\hline Ames toxicity & No & No & No \\
\hline Minnow toxicity & $0.69 \log \mathrm{mM}$ & $-1.164 \log \mathrm{mM}$ & $-1.14 \log \mathrm{mM}$ \\
\hline Carcino mouse & No & No & No \\
\hline \multicolumn{4}{|l|}{ Excretion } \\
\hline Total clearance & $0.763 \log \mathrm{mL} / \mathrm{min} / \mathrm{kg}$ & $0.026 \log \mathrm{mL} / \mathrm{min} / \mathrm{kg}$ & $0.031 \log \mathrm{mL} / \mathrm{min} / \mathrm{kg}$ \\
\hline Renal OCT2 substrate & No & No & $\mathrm{No}$ \\
\hline
\end{tabular}




\section{Materials and Methods}

\subsection{OGG1 Structure Retrieval and Preparation for Virtual Screening}

For the virtual screening, the complex OGG1-TH5487 was fetched from a protein data bank [46] (PDB-ID: 6RLW) [10] in UCSF Chimera 1.15 [47] and processed to prepare the OGG1 enzyme for virtual screening. The enzyme structure is determined by X-RAY diffraction method with a resolution of $2 \AA$, R-value free of 0.274 , and R-value work of 0.223 . All water molecules and co-crystallized TH5487 inhibitor were deleted from the structure except those present at the active pocket. The co-crystalized TH5487 inhibitor interactions with OGG1 enzyme are presented in Figure S5A. Subsequently, the structure was subjected to Dock Prep module of UCSF Chimera to add missing hydrogen atoms, charges, and complete missing side chains using Dunbrack 2010 rotamer library. The enzyme structure was then energy minimized through the Minimize structure module of UCSF Chimera where the steepest descent and conjugate gradient algorithms were run for 1000 cycles each. During this minimization process, the step size was kept at default of $0.02 \AA$. All standard residues of the enzyme were treated using an AMBER ff14SB force field [48] while charge addition used the Gasteiger method. The post-OGG1 enzyme structure was then loaded into PyRx 0.8 software [49] and converted into PDBQT (Protein Data Bank, Partial Charge (Q), \& Atom Type (T)).

\subsection{Inhibitors Library Preparation}

Different libraries of anti-cancer compounds (Selleckchem anti-cancer compound library I (3547 compounds) and II (921 compounds)) plus libraries of natural compounds including medicinal plant database (MDP3) ( $\sim 5000$ compounds) [50], Asinex targeted oncology database (4815 compounds), and comprehensive marine natural products database (CMNPD) ( 32,000 compounds) [51] were retrieved from their respective websites and filtered for non-toxic compounds in Discovery Studio 3.5 toxicity prediction module [52]. This filtration was important as toxicity is one of the leading causes among others resulting in failure of drugs during the development process [53]. The filtered molecules of each library were then imported to PyRx 0.8 [49] one by one where they were energy-minimized and converted to PDBQT.

\subsection{Molecular Docking for Inhibition Studies}

The docking process was done in Genetic Optimization for Ligand Docking (GOLD) 5.2 [54] and the same set of parameters were used in AutoDock Vina [55]. In GOLD, different scoring functions like ASP, CHEMPLP, and CHEM SCORE were considered. For comparative molecular docking, we utilized AutoDock Vina of PyRx 0.8 to carry out binding studies of all shortlisted drugs against OGG1 enzyme. The grid was box of size $(15 \times 15 \times 15$ along with the $\mathrm{XYZ})$ was set around Gly32 oxygen atom to guide binding of the libraries' molecules. Each molecule was allowed to generate 20 conformations at the defined OGG1 active pocket. The GOLD results were then sorted in ascending order and the highest GOLD score conformation of the molecules was selected and complexed with the enzyme. For validation, the co-crystalized TH5487 molecule, and two other Controls like SU0268 and O8 were docked to the receptor enzyme using the same procedure and the output conformation as compared to the original to get affirmation on the docking procedure. The docked TH5487 chemical interactions with pre-energy minimized OGG1 enzyme are given in Figure S5B. For negative Control, TH2840 or TH5411 were used [https://www.ncbi.nlm.nih.gov/pmc/articles/PMC6645780/] (8 December 2021). The top 10 solutions of GOLD were compared, and the best common binders were selected for downward computational studies.

\subsection{Molecular Dynamics Simulation Study}

For the molecular dynamic simulations, we employed AMBER20 software package [56]. Force fields like ff14SB force field were applied to generate parameters of the OGG1 whereas GAFF force field [57] and AM1-BCC atomic charges were run for ligands pa- 
rameterization. The systems solvation was conducted in TIP3P water model of size $12.0 \AA$ and then $\mathrm{NaCl}$ mediated neutralization at the concentration of $0.10 \mathrm{M}$ was performed. As an example, the water box solvating Control complex is presented in Figure S6. Energy of the systems was minimized through 1500 steps of steepest gradient and 1500 steps of conjugate gradient methods. Each system was heated for a time scale of 50 ps keeping the temperature constant $(300 \mathrm{~K})$. Equilibration of the systems was then achieved for 50 ps using periodic boundary conditions considering constant pressure and Langevin thermostat [58]. Following systems equilibrium, NPT ensemble was used to conduct molecular dynamic simulation for a time scale of $100 \mathrm{~ns}$ with a temperature of $310 \mathrm{~K}$. To constrain the bonds at their equilibrium lengths, we used the SHAKE algorithm [59]. To define van der Waals interactions, a cut-off value of $10-\AA$ cut-off was considered, and a PME method [60] was employed for defining the electrostatic forces. Subsequently, for understanding systems dynamics different AMBER modules were used including CPPTRAJ [61] and MMPBSA.py [62]. For frame visualization at different nanoseconds, UCSF Chimera [47] and Discovery Studio v21.1.0.20298 [52] were utilized. Radial distribution function (RDF) plots were generated for chemical interactions that play a significant role in anchoring the compound at the docked site and increase intermolecular stability $[35,63]$.

\subsection{Estimating $M M / G B S A$ and $M M / P B S A$ Binding Free Energies}

To determine both total binding free energy and per-residue decomposition of selected complexes MM/GBSA and MM/PBSA approaches were used [24]. This was accomplished by running MMPBSA.py module of AMBER20 on all simulated trajectories of the systems. For the protocol, 500 frames from each system trajectories were picked and processed through the following equation,

$\Delta \mathrm{G}$ binding $=\Delta \mathrm{G}$ enzyme-compound complex $-[\Delta \mathrm{G}$ enzyme $+\Delta \mathrm{G}$ compound $]$

The entropy energy of each complex was determined using a bash script applied in a previous study [64].

\subsection{WaterSwap Binding Energy Predictions}

The docked complexes were then subjected to WaterSwap based binding energy predictions [26,27]. WaterSwap from the Sire package was used to calculate binding free energy for default 1000 iterations considering 25 million moves of Monte Carlo sampling across different $16 \lambda \mathrm{s}$ at pressure $1 \mathrm{~atm}$ and temperature $198.15 \mathrm{~K}$ for each replica. The binding free energy was investigated using three different algorithms: thermodynamic integration (TI), free energy perturbation (FEP), and Bennett's acceptance ratio (BAR). Deviation in the net energy value of $1 \mathrm{kcal} / \mathrm{mol}$ indicates a good degree of systems convergence [65].

\subsection{In Silico Site-directed Mutagenesis}

Alanine scanning analysis was further performed for OGG1 enzyme residues that are seen consistently important for interactions with the compounds [40]. Key residues of OGG1 enzyme were manually mutated to Alanine and the binding energy of the enzymecompounds complexes was re-estimated using AMBER MM/GBSA method. The binding energy difference between native and mutants are termed as $\Delta \Delta G_{\text {bind }}$ and calculated as:

$\Delta \Delta$ Gbind $=\Delta G$ binding energy of native Type $-\Delta G$ binding energy of mutants

More stability of the mutants can be inferred by a lower $\Delta G_{b i n d}$ value and vice versa.

\subsection{Predictions about Compounds Pharmacokinetics}

In silico predictions about compounds, pharmacokinetics were done using online SWISSADME [42] and pkCSM servers [41]. 


\section{Conclusions}

Computer aided drug designing (CADD) techniques have been useful in discovery, developing and analyzing biological active drugs [12]. Compared to experimental drug designing, CADD significantly shortens the drug development time, reduces extra cost and increases the chances of successful design of new drugs. In this study, different approaches of CAAD are utilized to identify inhibitory molecules against the OGG1 enzyme, which is a potential target for treating cancer. As a result of structure-based virtual screening of both natural and synthetic compounds libraries against the enzyme, two drug molecules; $([\mathrm{O}-] \mathrm{C} 1=\mathrm{C}(\mathrm{CC} 2=\mathrm{CC}=\mathrm{CC}=\mathrm{C} 2) \mathrm{SC}(=[\mathrm{N}+] 1 \mathrm{CC}(=\mathrm{O}) \mathrm{NC} 3=\mathrm{NC}=\mathrm{C}(\mathrm{CC} 4=\mathrm{CC}=\mathrm{CC}=\mathrm{C} 4) \mathrm{S} 3) \mathrm{S}$ and $\mathrm{CCCN}(\mathrm{CCC})[\mathrm{S}](=\mathrm{O})(=\mathrm{O}) \mathrm{C} 1=\mathrm{CC}=\mathrm{C}(\mathrm{C}=\mathrm{C} 1) \mathrm{C}(=\mathrm{O}) \mathrm{NNC} 2=\mathrm{NC} 3=\mathrm{CC}=\mathrm{C}(\mathrm{Br}) \mathrm{C}=\mathrm{C} 3 \mathrm{C}(=\mathrm{N} 2) \mathrm{C} 4=$ $\mathrm{CC}=\mathrm{CC}=\mathrm{C} 4)$ from Selleckchem library were identified as high affinity inhibitory molecules. Both the molecules are showing stable interactions with the enzyme active pocket residues and accomplished stable binding pose as the simulation time proceeds. The compounds strong binding to the enzyme is supported by multiple hydrogen bonds that anchor the compounds in the docked pocket. The enzyme-compounds complexes atomic level interactions are dominated by both electrostatic and van der Waals energies and revealed good systems equilibrium. Moreover, the compounds have an acceptable pharmacokinetics profile thus making them good candidates to be considered in additional structural optimization to get desired biological activity. The compounds are of different chemical nature than those reported previously and have shown stronger binding and well fitting inside the OGG1 pocket. Though these computational findings are promising, yet experimental validation to uncover true biological potency of the compounds to block the function of OGG1 enzyme still needed to be performed.

Supplementary Materials: Figure S1. Binding mode of top 10 hits at the active pocket of OGG1 enzyme predicted using GOLD. Figure S2. Duplicate RMSD of the systems with a different initial velocity. Figure S3. Superimposition of last frame of molecular dynamics simulation over docked enzyme-compound structure depicting stability of Top-1 binding. Figure S4. Superimposition of last frame of molecular dynamics simulation over docked enzyme-compound structure depicting stability of Top-2 binding. Figure S5. Co-crystalized TH5487 chemical interactions (A) and docked TH5487 chemical interactions. Figure S6. Submerged Control-OGG1 complex (surface blue magenta) in TIP3P water box.

Author Contributions: Conceptualization, Z.T.M. and G.L.; methodology, Z.T.M.; validation, M.H.A., N.R.J., D.S.M., A.M.A. and G.L.; formal analysis, Z.T.M.; data curation, Z.T.M., M.H.A., N.R.J., D.S.M. and A.M.A.; writing—original draft preparation, Z.T.M.; writing—review and editing, M.H.A., N.R.J., D.S.M., A.M.A. and G.L.; supervision, G.L.; project administration, G.L.; funding acquisition, G.L. All authors have read and agreed to the published version of the manuscript.

Funding: This research was funded by the National Natural Science Foundation of China (grant numbers: 31770333, 31370329, and 11631012).

Data Availability Statement: The data presented in this study are available within the article.

Acknowledgments: Authors would like to acknowledge Shaanxi Normal University, Xi'an, China, for providing facilities for this research.

Conflicts of Interest: The authors declare no conflict of interest.

\section{References}

1. Phaniendra, A.; Jestadi, D.B.; Periyasamy, L. Free radicals: Properties, sources, targets, and their implication in various diseases. Indian J. Clin. Biochem. 2015, 30, 11-26. [CrossRef]

2. Kumari, S.; Badana, A.K.; Malla, R. Reactive oxygen species: A key constituent in cancer survival. Biomark. Insights 2018, 13, 1177271918755391. [CrossRef]

3. Valko, M.; Leibfritz, D.; Moncol, J.; Cronin, M.T.D.; Mazur, M.; Telser, J. Free radicals and antioxidants in normal physiological functions and human disease. Int. J. Biochem. Cell Biol. 2007, 39, 44-84. [CrossRef]

4. Poli, G.; Leonarduzzi, G.; Biasi, F.; Chiarpotto, E. Oxidative stress and cell signalling. Curr. Med. Chem. 2004, 11, 1163-1182. [CrossRef] 
5. Steenken, S.; Jovanovic, S.V. How easily oxidizable is DNA? One-electron reduction potentials of adenosine and guanosine radicals in aqueous solution. J. Am. Chem. Soc. 1997, 119, 617-618. [CrossRef]

6. Damia, G.; D'Incalci, M. Targeting DNA repair as a promising approach in cancer therapy. Eur. J. Cancer 2007, 43, 1791-1801. [CrossRef]

7. Murai, J.; Shar-yin, N.H.; Das, B.B.; Renaud, A.; Zhang, Y.; Doroshow, J.H.; Ji, J.; Takeda, S.; Pommier, Y. Trapping of PARP1 and PARP2 by clinical PARP inhibitors. Cancer Res. 2012, 72, 5588-5599. [CrossRef]

8. Mansour, W.Y.; Rhein, T.; Dahm-Daphi, J. The alternative end-joining pathway for repair of DNA double-strand breaks requires PARP1 but is not dependent upon microhomologies. Nucleic Acids Res. 2010, 38, 6065-6077. [CrossRef]

9. Ronson, G.E.; Piberger, A.L.; Higgs, M.R.; Olsen, A.L.; Stewart, G.S.; McHugh, P.J.; Petermann, E.; Lakin, N.D. PARP1 and PARP2 stabilise replication forks at base excision repair intermediates through Fbh1-dependent Rad51 regulation. Nat. Commun. 2018, 9, 746. [CrossRef] [PubMed]

10. Visnes, T.; Benítez-Buelga, C.; Cázares-Körner, A.; Sanjiv, K.; Hanna, B.M.F.; Mortusewicz, O.; Rajagopal, V.; Albers, J.J.; Hagey, D.W.; Bekkhus, T.; et al. Targeting OGG1 arrests cancer cell proliferation by inducing replication stress. Nucleic Acids Res. 2020, 48, 12234-12251. [CrossRef]

11. Hanna, B.M.F.; Helleday, T.; Mortusewicz, O. OGG1 Inhibitor TH5487 Alters OGG1 Chromatin Dynamics and Prevents Incisions. Biomolecules 2020, 10, 1483. [CrossRef]

12. Yu, W.; MacKerell, A.D. Computer-aided drug design methods. In Antibiotics; Springer: Manhattan, NY, USA, $2017 ;$ pp. 85-106.

13. Suleman, M.; ul Qamar, M.T.; Shoaib Saleem, S.A.; Ali, S.S.; Khan, H.; Akbar, F.; Khan, W.; Alblihy, A.; Alrumaihi, F.; Waseem, M. Mutational Landscape of Pirin and Elucidation of the Impact of Most Detrimental Missense Variants That Accelerate the Breast Cancer Pathways: A Computational Modelling Study. Front. Mol. Biosci. 2021, 8, 692835. [CrossRef]

14. Ismail, S.; Shahid, F.; Khan, A.; Bhatti, S.; Ahmad, S.; Naz, A.; Almatroudi, A.; ul Qamar, M.T. Pan-Vaccinomics Approach Towards a Universal Vaccine Candidate Against WHO Priority Pathogens to Address Growing Global Antibiotic Resistance. Comput. Biol. Med. 2021, 136, 104705. [CrossRef]

15. Alamri, M.A.; ul Qamar, M.T.; Afzal, O.; Alabbas, A.B.; Riadi, Y.; Alqahtani, S.M. Discovery of anti-MERS-CoV small covalent inhibitors through pharmacophore modeling, covalent docking and molecular dynamics simulation. J. Mol. Liq. 2021, 330, 115699. [CrossRef]

16. Mumtaz, A.; Ashfaq, U.A.; Qamar, M.T.; Anwar, F.; Gulzar, F.; Amjad, M.A.; Saari, N.; Pervez, M.T. MPD3: A useful medicinal plants database for drug designing. Nat. Prod. Res. 2020, 34, 1051. [CrossRef]

17. RK, M.; AK, N. In silico evaluation of multispecies toxicity of natural compounds. Drug Chem. Toxicol. 2019, $21,1-7$.

18. Khan, W.; Ashfaq, U.A.; Aslam, S.; Saif, S.; Aslam, T.; Tusleem, K.; Maryam, A.; ul Qamar, M.T. Anticancer screening of medicinal plant phytochemicals against Cyclin-Dependent Kinase-2 (CDK2): An in-silico approach. Adv. Life Sci. $2017,4,113-119$.

19. Riaz, M.; Ashfaq, U.A.; Qasim, M.; Yasmeen, E.; Ul Qamar, M.T.; Anwar, F. Screening of medicinal plant phytochemicals as natural antagonists of p53-MDM2 interaction to reactivate p53 functioning. Anticancer. Drugs 2017, 28, 1032-1038. [CrossRef] [PubMed]

20. Morris, G.M.; Lim-Wilby, M. Molecular docking. In Molecular Modeling of Proteins; Springer: Manhattan, NY, USA, 2008; pp. 365-382.

21. Khalid, R.R.; ul Qamar, M.T.; Maryam, A.; Ashique, A.; Anwar, F.; Geesi, M.H.; Siddiqi, A. Comparative Studies of the Dynamics Effects of BAY60-2770 and BAY58-2667 Binding with Human and Bacterial H-NOX Domains. Molecules 2018, 23, 2141. [CrossRef]

22. Durrant, J.D.; McCammon, J.A. Molecular dynamics simulations and drug discovery. BMC Biol. 2011, 9, 71. [CrossRef] [PubMed]

23. Muneer, I.; Ul Qamar, M.T.; Tusleem, K.; Abdul Rauf, S.; Hussain, H.M.J.; Siddiqi, A.R. Discovery of selective inhibitors for cyclic AMP response element-binding protein: A combined ligand and structure-based resources pipeline. Anticancer. Drugs 2019, 30 , 363-373. [CrossRef]

24. Genheden, S.; Ryde, U. The MM/PBSA and MM/GBSA methods to estimate ligand-binding affinities. Expert Opin. Drug Discov. 2015, 10, 449-461. [CrossRef] [PubMed]

25. Durdagi, S.; Tahir ul Qamar, M.; Salmas, R.E.; Tariq, Q.; Anwar, F.; Ashfaq, U.A. Investigating the molecular mechanism of staphylococcal DNA gyrase inhibitors: A combined ligand-based and structure-based resources pipeline. J. Mol. Graph. Model. 2018, 85, 122-129. [CrossRef]

26. Woods, C.J.; Malaisree, M.; Michel, J.; Long, B.; McIntosh-Smith, S.; Mulholland, A.J. Rapid decomposition and visualisation of protein-ligand binding free energies by residue and by water. Faraday Discuss. 2014, 169, 477-499. [CrossRef]

27. Woods, C.J.; Malaisree, M.; Hannongbua, S.; Mulholland, A.J. A water-swap reaction coordinate for the calculation of absolute protein-ligand binding free energies. J. Chem. Phys. 2011, 134, 02B611. [CrossRef]

28. Khan, R.J.; Jha, R.K.; Amera, G.; Jain, M.; Singh, E.; Pathak, A.; Singh, R.P.; Muthukumaran, J.; Singh, A.K. Targeting SARS-Cov-2: A systematic drug repurposing approach to identify promising inhibitors against 3C-like Proteinase and 2'O-RiboseMethyltransferase. J. Biomol. Struct. Dyn. 2020, 39, 2679-2692. [CrossRef] [PubMed]

29. Maiorov, V.N.; Crippen, G.M. Significance of root-mean-square deviation in comparing three-dimensional structures of globular proteins. J. Mol. Biol. 1994, 235, 625-634. [CrossRef]

30. Kuzmanic, A.; Zagrovic, B. Determination of ensemble-average pairwise root mean-square deviation from experimental B-factors. Biophys. J. 2010, 98, 861-871. [CrossRef] 
31. Pant, S.; Singh, M.; Ravichandiran, V.; Murty, U.S.N.; Srivastava, H.K. Peptide-like and small-molecule inhibitors against Covid-19. J. Biomol. Struct. Dyn. 2020, 39, 1-15. [CrossRef]

32. Lobanov, M.Y.; Bogatyreva, N.S.; Galzitskaya, O. V Radius of gyration as an indicator of protein structure compactness. Mol. Biol. 2008, 42, 623-628. [CrossRef]

33. Iqbal, S.; Shamim, A.; Azam, S.S.; Wadood, A. Identification of potent inhibitors for chromodomain-helicase- DNA-binding protein 1-like through moleculardocking studies. Med. Chem. Res. 2016, 25, 2924-2939. [CrossRef]

34. Wade, R.C.; Goodford, P.J. The role of hydrogen-bonds in drug binding. Prog. Clin. Biol. Res. 1989, 289, 433-444. [PubMed]

35. Abbasi, S.; Raza, S.; Azam, S.S.; Liedl, K.R.; Fuchs, J.E. Interaction mechanisms of a melatonergic inhibitor in the melatonin synthesis pathway. J. Mol. Liq. 2016, 221, 507-517. [CrossRef]

36. Raza, S.; Azam, S.S. AFD: An application for bi-molecular interaction using axial frequency distribution. J. Mol. Model. 2018, 24, 1-8. [CrossRef] [PubMed]

37. Humphrey, W.; Dalke, A.; Schulten, K. VMD: Visual molecular dynamics. J. Mol. Graph. 1996, 14, 33-38. [CrossRef]

38. Hou, T.; Wang, J.; Li, Y.; Wang, W. Assessing the Performance of the MM_PBSA and MM_GBSA Methods. 1. The accuracy of binding free energy calculations based on molecular dynamics simulations. J. Chem. Inf. Modeling 2011, 51, 69-82. [CrossRef]

39. Joshi, R.S.; Jagdale, S.S.; Bansode, S.B.; Shankar, S.S.; Tellis, M.B.; Pandya, V.K.; Chugh, A.; Giri, A.P.; Kulkarni, M.J. Discovery of Potential Multi-Target-Directed Ligands by Targeting Host-specific SARS-CoV-2 Structurally Conserved Main Protease\$. J. Biomol. Struct. Dyn. 2021, 39, 3099-3114. [CrossRef] [PubMed]

40. Abro, A.; Azam, S.S. Binding free energy based analysis of arsenic (+ 3 oxidation state) methyltransferase with Sadenosylmethionine. J. Mol. Liq. 2016, 220, 375-382. [CrossRef]

41. Pires, D.E.V.; Blundell, T.L.; Ascher, D.B. pkCSM: Predicting small-molecule pharmacokinetic and toxicity properties using graph-based signatures. J. Med. Chem. 2015, 58, 4066-4072. [CrossRef]

42. Daina, A.; Michielin, O.; Zoete, V. SwissADME: A free web tool to evaluate pharmacokinetics, drug-likeness and medicinal chemistry friendliness of small molecules. Sci. Rep. 2017, 7, 42717. [CrossRef]

43. Jia, C.-Y.; Li, J.-Y.; Hao, G.-F.; Yang, G.-F. A drug-likeness toolbox facilitates ADMET study in drug discovery. Drug Discov. Today 2019, 25, 248-258. [CrossRef]

44. Veber, D.F.; Johnson, S.R.; Cheng, H.Y.; Smith, B.R.; Ward, K.W.; Kopple, K.D. Molecular properties that influence the oral bioavailability of drug candidates. J. Med. Chem. 2002, 45, 2615-2623. [CrossRef]

45. Whitty, A. Growing PAINS in academic drug discovery. Future Med. Chem. 2011, 3, 797-801. [CrossRef] [PubMed]

46. Sussman, J.L.; Lin, D.; Jiang, J.; Manning, N.O.; Prilusky, J.; Ritter, O.; Abola, E.E. Protein Data Bank (PDB): Database of threedimensional structural information of biological macromolecules. Acta Crystallogr. Sect. D Biol. Crystallogr. 1998, 54, 1078-1084. [CrossRef] [PubMed]

47. Pettersen, E.F.; Goddard, T.D.; Huang, C.C.; Couch, G.S.; Greenblatt, D.M.; Meng, E.C.; Ferrin, T.E. UCSF Chimera-A visualization system for exploratory research and analysis. J. Comput. Chem. 2004, 25, 1605-1612. [CrossRef] [PubMed]

48. Maier, J.A.; Martinez, C.; Kasavajhala, K.; Wickstrom, L.; Hauser, K.E.; Simmerling, C. ff14SB: Improving the accuracy of protein side chain and backbone parameters from ff99SB. J. Chem. Theory Comput. 2015, 11, 3696-3713. [CrossRef] [PubMed]

49. Dallakyan, S.; Olson, A.J. Small-molecule library screening by docking with PyRx. In Chemical Biology; Springer: Manhattan, NY, USA, 2015; pp. 243-250.

50. Mumtaz, A.; Ashfaq, U.A.; ul Qamar, M.T.; Anwar, F.; Gulzar, F.; Ali, M.A.; Saari, N.; Pervez, M.T. MPD3: A useful medicinal plants database for drug designing. Nat. Prod. Res. 2017, 31, 1228-1236. [CrossRef]

51. Lyu, C.; Chen, T.; Qiang, B.; Liu, N.; Wang, H.; Zhang, L.; Liu, Z. CMNPD: A comprehensive marine natural products database towards facilitating drug discovery from the ocean. Nucleic Acids Res. 2021, 49, D509-D515. [CrossRef]

52. Biovia, D.S. Discovery Studio Visualizer; BIOVIA Discovery Studio: San Diego, CA, USA, 2017.

53. Spławiński, J.; Kuźniar, J.; Filipiak, K.; Zieliński, W. Evaluation of drug toxicity in clinical trials. Sci. Eng. Ethics 2006, 12, 139-145. [CrossRef]

54. Jones, G.; Willett, P.; Glen, R.C.; Leach, A.R.; Taylor, R. Development and validation of a genetic algorithm for flexible docking. J. Mol. Biol. 1997, 267, 727-748. [CrossRef]

55. Trott, O.; Olson, A.J. AutoDock Vina: Improving the speed and accuracy of docking with a new scoring function, efficient optimization, and multithreading. J. Comput. Chem. 2010, 31, 455-461. [CrossRef] [PubMed]

56. Case, D.A.; Belfon, K.; Ben-Shalom, I.; Brozell, S.R.; Cerutti, D.; Cheatham, T.; Cruzeiro, V.W.D.; Darden, T.; Duke, R.E.; Giambasu, G.; et al. d 2020. 2020. Available online: https:/ / ambermd.org/doc12/Amber20.pdf (accessed on 8 December 2021).

57. Wang, J.; Wolf, R.M.; Caldwell, J.W.; Kollman, P.A.; Case, D.A. Development and testing of a general amber force field. J. Comput. Chem. 2004, 25, 1157-1174. [CrossRef] [PubMed]

58. Izaguirre, J.A.; Catarello, D.P.; Wozniak, J.M.; Skeel, R.D. Langevin stabilization of molecular dynamics. J. Chem. Phys. 2001, 114, 2090-2098. [CrossRef]

59. Kräutler, V.; Van Gunsteren, W.F.; Hünenberger, P.H. A fast SHAKE algorithm to solve distance constraint equations for small molecules in molecular dynamics simulations. J. Comput. Chem. 2001, 22, 501-508. [CrossRef]

60. Petersen, H.G. Accuracy and efficiency of the particle mesh Ewald method. J. Chem. Phys. 1995, 103, 3668-3679. [CrossRef]

61. Roe, D.R.; Cheatham III, T.E. PTRAJ and CPPTRAJ: Software for processing and analysis of molecular dynamics trajectory data. J. Chem. Theory Comput. 2013, 9, 3084-3095. [CrossRef] 
62. Miller, B.R.; McGee, T.D.; Swails, J.M.; Homeyer, N.; Gohlke, H.; Roitberg, A.E. MMPBSA.py: An efficient program for end-state free energy calculations. J. Chem. Theory Comput. 2012, 8, 3314-3321. [CrossRef]

63. Kouetcha, D.N.; Ramézani, H.; Cohaut, N. Ultrafast scalable parallel algorithm for the radial distribution function histogramming using MPI maps. J. Supercomput. 2017, 73, 1629-1653. [CrossRef]

64. Duan, L.; Liu, X.; Zhang, J.Z.H. Interaction entropy: A new paradigm for highly efficient and reliable computation of proteinligand binding free energy. J. Am. Chem. Soc. 2016, 138, 5722-5728. [CrossRef]

65. Kiani, Y.S.; Ranaghan, K.E.; Jabeen, I.; Mulholland, A.J. Molecular Dynamics Simulation Framework to Probe the Binding Hypothesis of CYP3A4 Inhibitors. Int. J. Mol. Sci. 2019, 20, 4468. [CrossRef] 